\title{
Students' Learning and Outcomes as Indicators of Quality Teaching in Higher Education
}

\author{
Assia Baghdadi \\ Department of English, M'sila University, Algeria
}

\begin{abstract}
Quality Teaching is believed to be one of the controversial terms that raised debates among the scholars who have been divided into those who regard quality primarily as an outcome, and those who view it as a property. Another trend considers teaching as the never ending process of reduction of defects and so Quality Teaching can never be totally grasped and appraised. Accordingly, the issue of measuring quality teaching is highly crucial, and the choice of valid indicators to assess the quality of teaching is not yet standardized and is still challenging. Furthermore the emerging consensus explores that traditional teacher evaluation methods are inadequate and inconsequential in ensuring a quality teaching workforce. In this regard, the current paper attempts to introduce firstly a set of competitive definitions of quality teaching, and secondly shedding light on the new criteria for evaluation that rely more on student learning and outcomes, and also on multiple measures that are expected to ensure a more holistic assessment of teacher performance and initiatives. Finally, a series of considerations and recommendations are stated for the betterment of quality teaching.
\end{abstract}

Keywords: assessment, learners, measurement, performance, university.

\section{Introduction}

Higher education systems and institutions worldwide have been facing continuous changes which triggered them to undergo extensive reform with the agenda of improving quality teaching (Doyle, 2006; Guthrie \& Neumann, 2007). However, ensuring teaching quality in HE becomes a critical issue and the debate on quality teaching is intensified because of the lack of a clear definition of 'quality teaching' and the related difficulties of setting welldefined indicators that are directly linked to the quality of teaching as such, and also because of the lack of one agreed approach for measuring it (Strang et al., 2016). Actually, this quality ensurance becomes increasingly challenging after two major issues in particular. The first is the shift undergone over the past decade by HE from the traditional content-based approach to the learner-centered approach which positions the learners at the centre of the learning process and empowers them to take responsibility for what they learn (Robertson, 2001). The second is the overwhelming emphasis on learning outcomes, which provides a way of focusing attention on students' real achievements, and which reflects a more objective and genuine measure of the value and quality of education (Barr and Tagg, 1995), and which has given rise to issues and concerns about the undue emphasis on the instrumental and economic importance of education, measured in terms of quality and effectiveness (Bagnall, 2009).

In this regard, the current paper seeks, firstly, to introduce a set of competitive definitions of quality teaching and its various indicators and, secondly, to shed light on the new evaluation standards that focus more on learning-based outcomes approach by setting forth its key 


\section{$3^{\text {rd }}$ International Conference on Research in EDUCATION}

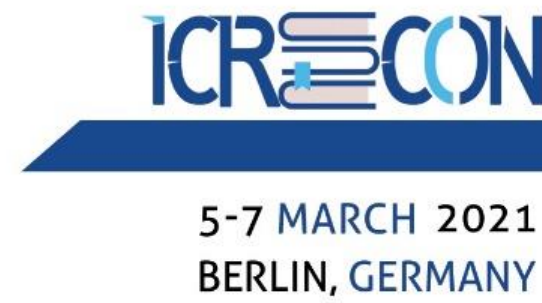

elements, its benefits and drawbacks and, finally, suggesting some of recommendations in applying it.

\section{Quality Teaching definition}

There was no clear definition of the concept of quality teaching, as it relates to the concept of quality, which is itself a multi-layered and nuanced term that describes an outcome, a property or a process (Biggs, 2001). According to Harvey and Green (1993) definition, four distinct definitions were assigned to quality. First, it refers to "excellence" which is based on creating an environment in which the best prosper regardless of others. Second, by creating an internalized set of values that ensures the successful and efficient use of resources, quality can refer to' value for money'. Third, by establishing a common understanding of intent and how to accomplish it, it can be interpreted as "fitness for purpose". The last definition of Harvey \& Green is that quality is seen as "transforming" by ensuring that top graduate students are prepared (enhanced and empowered) for significant graduate jobs and that top researchers are fully supported and encouraged to attract and deliver major research projects.

In an other definition proposed by UNESCO (2003), quality can be based on three key principles : the need for relevance, for equality of access and outcomes and for the proper observance of individual rights. However, it seen by Hau (1996) in a broader sense as the outcome of a never-ending phase of reduction and removal of defects. Of all the definitions listed above, it is not surprising that the idea of' Quality Teaching' has been given several meanings each representing a specific vision and stance.

With respect to higher education, scholars introduce quality in higher education as the process of quality enhancement. Argyris \& Schön (1974) argue in this regard that progress in the quality of higher education can typically be analyzed in terms of a set of indicators classified under context indicators, specific input indicators, social or institutional process indicators and output or outcomes indicators.

Context measures, according to Scheerens, Luyten, and van Ravens (2011), are those that provide information on contextual factors affecting learning, such as student characteristics, socio-economic conditions, the status of the teaching profession, cultural aspects, and local community concerns. Context indicators are hard to quantify, as they include qualitative considerations. Common data collection methods include surveys, observation in the classroom, inspection reports, and self-evaluations.

Scheerens, Luyten, and van Ravens (2011) argue that input indicators are used to assess the deployment and usage of resources to promote learning. This type of indicators report if the planned financial, material and human resources are provided in the planned quantities at all levels of the system. The discrepancies between producing inputs and ensuring that they are accessible at the endpoint can be one challenge. For instance, the textbook/pupil ratio can be calculated in terms of the number of textbooks distributed or in terms of the number of textbooks used in classrooms. In some cases there may be a difference between the two statistics in some situations.

In contrast, process indicators are used to measure how the instructional program's activities have been carried out. This includes how basic educational processes are carried out in practice, such as the application of standards, the quality of teaching, time on task, the school setting, and educational leadership. Qualitative issues are often concerned with process indicators which can be gathered by surveys and pedagogical observations, inspection reports and selfassessments (Scheerens, Luyten, and van Ravens, 2011). They shed light on how the education 


\section{$3^{\text {rd }}$ International Conference on Research in EDUCATION}

system performs in terms of subject knowledge, expertise, repetition, advancement and completion rates.

Performance indicators or output indicators, according to Scheerens, Luyten, and van Ravens (2011) are the ones which typically provide the most relevant data to understand whether the quality of education and learning outcomes are improving as expected, and which can be collected by national evaluations, international assessments, surveys, and systematic field observations.

Almost all of these indicators are imperative and quality should not be assessed from any narrow point of view, especially in light of the growing demands for transparency that have led, in recent years, to the rapid dissemination of different types of outcome-based education in which quality and efficiency performance indicators are essential and are the means of achieving the specific outcome in a system of 'outcomes-driven education (Bagnall, 1994). The following section will identify outcomes-based educatin (OBE) and provide a detailed review on it.

\section{Outcomes-based education}

A learning outcome is defined by Watson (2002, p. 208) as : " being something that students can do now that they have not been able to do before... a shift in people as a result of a learning experience ". A learning outcome is described by Adams (2004) as a description of what a learner would have learned at the end of a period of study. Theoretically, learning outcomes can encapsulate a broad spectrum of skills, abilities and behavioral types. In this way, we can have outcomes of learning that describe: specific skills, ways of thinking, such as analysis, and ways of behaving. The world expert on outcome-based eduction is considered by many to be William Spady who provides a detailed definition of learning outcomes:

Learning outcomes are the results we desire from students that lead to culminating demonstrations. These results and their demonstrations occur at or after the end of a significant learning experience; hence the term "culminating."This means that an outcome is not a collection or average of previous learning experi-ences, but a manifestation of what learners can do once they have had andcompleted all of those experiences. This also means that outcomes are not simply the things students believe, feel, remember, know, or understand these and other similar things are all internal mental processes, rather than clear demonstrations of learning. Instead, outcomes are what students actually can do with what they know and understand" (Spady, 1994, p. 59)

The most well-known contribution to the development of outcome-based curricula was the publication in 1956 of Benjamin Bloom's A Taxonomy of Cognitive Objectives, which proposed a structure for classifying learning in cognitive terms that articulated the different types of student thinking (i.e. knowledge, comprehension, application, analysis, synthesis and evaluation). After being recently revised by Anderson and Krathwohl (2001), this taxonomy has lined up the time test and underpins the design of many outcomes-based curricula around the world (Coates, 2000).

As part of the broader accountability system, learning outcomes approach has been implemented at various levels of education systems around the world. In the early 1990s, 
Australia and South Africa introduced OBE policies. Since 1994, the United States has had an OBE policy in place that has been adapted through the years. Hong Kong adopted an outcomebased strategy for its universities in 2005. In 2008, Malaysia adopted OBE in all its public school systems. The Washington Accord was founded in 1989 in an international attempt to recognize OBE; it is an agreement to accept degrees in undergraduate engineering that have been earned using OBE methods. Since 2017, the full signatories are Australia, Canada, Taiwan, Hong Kong, India, Ireland, Japan, Korea, Malaysia, New Zealand, Russia, Singapore, South Africa, Sri Lanka, Turkey, the United Kingdom, Pakistan, China and the United States (Gosling and Moon, 2001). In Europe, Adam (2004, 2006) mentions the cross-national standard alignment initiative currently underway in Europe under the auspices of the Bologna Process, which aims to establish a shared model for European higher education in which learning outcomes can play an important role. Accordingly, the goal for 2010 was to focus all programs provided by higher education institutions on the idea of learning outcomes, and to update the curriculum to reflect this. All degrees (Bachelor and Masters) will be defined in terms of learning outcomes, workload, level, skills and profile via the development of national qualification frameworks Kennedy, Hyland and Ryan, 2006). A detailed description of the OB approach is set forth below.

\section{The key components of the outcome-based approach}

Sound outcome-based models contain many components that work together to modify how institutions function and promote student learning progress. These key elements are depicted graphically in a Pyramid suggesting the main OBE elements proposed by Spady (1994): Paradigm of operating, two key purposes, three key Premises, four operating Principles, and five generic domains of Practice. Each of these levels is described below (Figure 1)

Figure (01) : The Outcoes-Based Education Pyramid

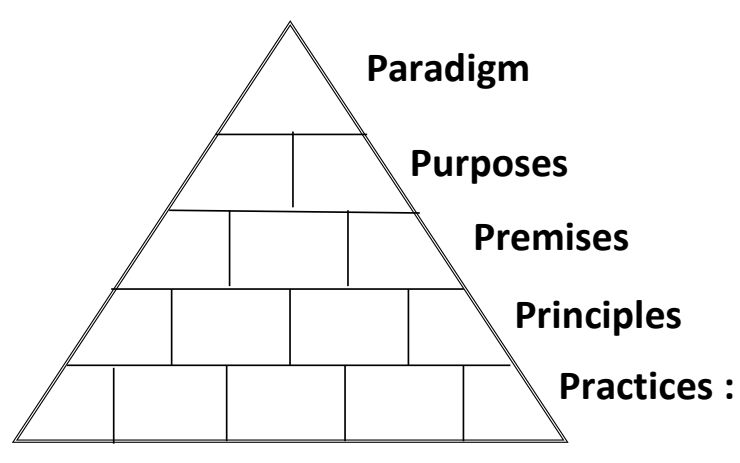

Define Outcomes

Design Curriculum

Deliver Instruction

Document results

Determine Advancement

( Spady, 1994, p. 19) 


\section{$3^{\text {rd }}$ International Conference on Research in EDUCATION}

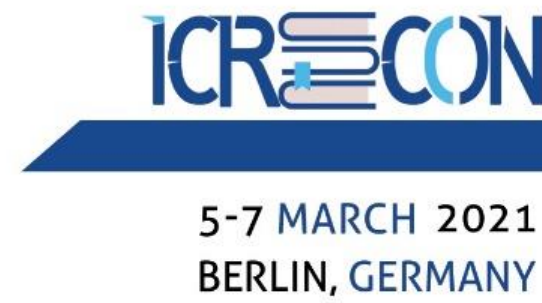

\subsection{The outcome-based education paradigm}

Strictly speaking, a paradigm is a way of viewing and a way of doing things that is compatible with that point of view. The OBE paradigm that forms decision-making and specific action patterns is the view that What and Whether students learn effectively is more important than When and How they learn something, i, e., making "accomplishing results" more relevant than just "providing services."

\subsection{The outcome-based education two purposes}

The two key objectives of the OBE in Spady's (1994) viewpoint reflect its fundamental "success for all" philosophy. The first objective is concerned with ensuring that when the learners leave the educational system, they are all armed with the knowledge, skills and qualities required to succeed. The second one is structuring and running institutions so that these outcomes can be obtained and improved by all students. These goals oppose the prevailing notion that different curricula and learning opportunities should be offered to students with different skills or abilities. Rather, institutions are required to fulfill their responsibility to provide all students with the skills and qualities necessary to meet challenges outside the University.

\subsection{The outcome-based education three premises}

OBE is based on three core assumptions informed by rigorous research and more than 30 years of educators' experience. Theses premises stress that all learners are able to learn and excel, but not in the same way on the same day. Even good learning encourages successful learning; and the factors that directly impact good learning are monitored by the institutions. These three premises function, therefore, as the rationale on which the actual implementation of OBE guided by the four principles outlined below essentially rests (Spady,1994)

To maintain the two aims and three premises into effect, those who actively and systematically control OBE's application guide what they do around four simple decisionmaking and action principles which are introduced in the following.

\subsection{The outcome-based education four principles}

At the core of OBE are these four principles which work together to improve the circumstances that enable students and teachers to be successful. These four principles are : Clarity of Focus, Expanded Opportunity, high Expectations, and Design Down (Spady, 1994)

This first principle is the most important and basic of the four. Without it, nothing can proceed in a truly outcome-based approach. In practice, this helps students and their teachers to work together as partners to achieve a visible and consistent objective.

The expanded opportunity at its most fundamental level enables managers to give students more than one opportunity to learn essential information and to show the learning. This method was originally applied by those who implemented OBE to small segments of learning that students could achieve in relatively short periods of time. The significant aspects of providing and expanding students' opportunities for learning and success incorporate, Time, Methods and Modalities, Operational Principles, Performance Standards, and Curriculum Access and Structuring.

High expectations, in turn, implies increasing the level of challenge to which learners are subjected and raising the level of appropriate output they need to attain to be considered "completed" or "qualified."

Design down means managers start their curriculum and educational planning where they actually want students to end up and build back from there. When one thinks of outcomes as falling into three main categories: culminating, enabling, and discrete, this challenging process 


\section{$3^{\text {rd }}$ International Conference on Research in EDUCATION}



becomes apparent according to Spady's (1994) viewpoint. That is when their official learning experiences are complete, what the curriculum expects all students to be able to do is decided by culminating performance. Enabling results are the primary building blocks on which those culminating outcomes rely. They are genuinely vital to the overall success of the outcomes of students. However, discrete outcomes are details of the curriculum that are "nice to know" but not necessary. The last level of the pyramid involves practices

\subsection{The outcome-based education practices}

Those practices entail determining outcomes, curriculum design, instruction delivery, results recording, and advancement determination.

\section{Outcomes-based Education approach levels}

In reality, approaches to learning outcomes have been used at several levels, ranging from instructional design where the individual student is the focus of interest, to institutions and programs where evaluation-based program improvement and quality assurance are major concerns (Ewell, 2008).

Learning outcomes are used at the individual student level to express what learners are supposed to do and how they are expected to display that accomplishment. As a result of engagement in a specific set of teaching and learning experiences, learning outcomes are defined as student attainment (Maureen, 2014). Three large categories of learning outcomes at the student level have been established in the classical work of Benjamin Bloom (19131993): cognitive, affective and psychomotor (Bloom et al., 1956). In general, cognitive results refer to the knowledge of content that students can understand, explain, analyze and apply. Skills outcomes, however, refer to the ability to do things in a job, like problem solving, efficiently speaking, or conducting certain technical procedures. Affective effects are connected to behaviors that typically require changes in beliefs or the formation of such ideals, such as ethical behaviour, compassion, or respect for others.

At the program or course level, learning outcomes are more broadly described as progress in studying a specific course or program (Ewell, 2008). Student improvement can take the form of employability and enhanced career mobility, better lifestyle, the ability to pursue further studies, or simply a fuller and happier life.

In more realistic words, however, learning outcomes at this level are also referred to as the qualification of particular standards of expertise, abilities, or capacity for a given profession. That is, at this level, student learning outcomes refer to the acquisition of the basic competencies gained by students when an instructional program or course is completed (Maureen, 2014).

Outcomes at the institutional level are typically linked to the evaluation of institutional quality assurance outcomes (Ewell, 2008). To this end, universities need to obtain proof of student abilities to prove the outcomes accomplishment at the institution level. Evidence here embraces the results of both quantitative and qualitative approaches to gathering information about student learning outcomes either in absolute or value-added terms (Maureen, 2014). In absolute terms, outcomes are referred to as attainment against existing standards (criterionreferenced assessment) or as the success of a person or group relative to others (normreferenced assessment). The findings here extend beyond student learning results to include quantitative measures to allow institutional performance evaluation. In value-addedterms, outcomes, however, can refer to 'before-after development' or 'improvement' as a result of the attendance of a student at a higher education institution. 


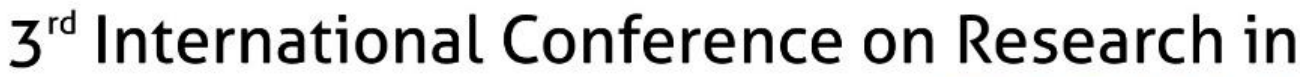 EDUCATION}

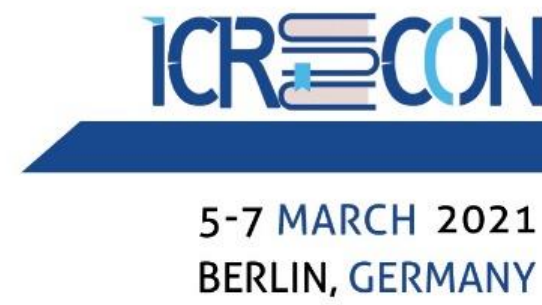

\section{OBE assessment system}

Over the past three decades, spady (1994) asserts that the students' grades and credentials have been increasingly connected to the kind of educational background and qualifications he or she has. However, from the outcome-based approach parents and the public can be provided with: 1) a substantial improvement in opportunities for students to learn things that will prepare them for entry to advanced education levels and boost their chances of success while they are there, and 2) certificates and transcripts that reliably record what they can do when they graduate.

In contrast to the points system based on uninterpretable symbolic or numerical labels that reflect the subjective judgments of individual teachers about divergent, unrelated items that occurred during a specific period of time, with OBE syetem, the chances are very high that most students learn to do very many things at very high quality levels spady (1994)

\section{The outcome-based education benefits and drawbacks}

There are both benefits and drawbacks associated with the implementation of interventions based on outcomes. A comprehension of both of them can help to make the principles and concepts of outcome schemes more concrete in the form of implementation in curriculum and instructional design. The following section will cast light on some of the prominent benefits and limits of OBE.

\subsection{The outcome-based education benefits}

OBE advocators have defended the following OBE advantages.

\subsubsection{The student at the centre of the learning process}

It has been contended that OBE positions the learner at the centre of the learning process by shifting away from the conception of content-based educational programs focus to a more student-centered approach. OBE practioners believe that learners would learn better and be more inspired and excited about what they are learning if they are given a real stake in their own learning (UDACE, 1989).

\subsubsection{Enhancing employability: benefits for employers and students}

Knight and Yorke (2004) argue that although HE's role in promoting economic growth and student employability may have been implicitly presumed for several years, it has become an explicit prerequisite for institutions only recently due to learning outcomes which allow universities to communicate the achievement of students beyond the narrow limits of content knowledge and to display other essential skills gained during the educational process. This claim was prominently confirmed by the employers who have long argued that they are more interested in what students can 'do' rather than what they 'know' and this added weight to the reasons for embracing an approach to learning outcomes (Jackson, 2000)

\subsubsection{A more open educational system: public information, quality and accountability}

The outcomes of learning can help institutions achieve government goals in two ways. First, the definition of study programs using clear learning outcomes enables government to 'benchmark' courses across the HE sector against nationally defined benchmarks, thus ensuring that universities offer high quality. Secondly, it is argued that the specification of study programs has shifted higher education from a highly selective, elitist system to a more open, multi-purpose mass system (Jackson, 2000). Moreover, information on the quality of the courses available can be easly obtained by both parents and potential students via publishing program specifications and league tables which rank universities against each other on various aspects of their provision.

\subsubsection{Clarity}

Focusing on outcomes will help to better convey the kind of learning anticipated at the end of a learning programme or course amongst different stakeholders. Students will know what is required of 


\section{$3^{\text {rd }}$ International Conference on Research in EDUCATION}

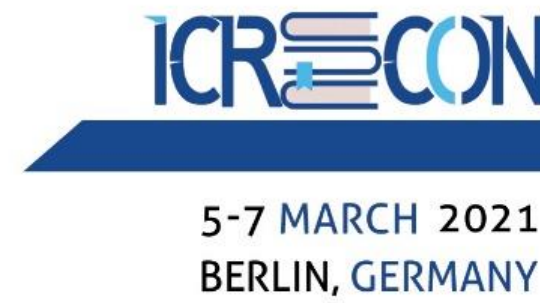

them; the same as teachers will know about the degree and expectations at which the outcomes ought to be taught. The criteria and expectations of a specific program or credential can be expressed at the institutional level in the form of a certification process for benchmarking with similar qualifications provided by other institutions. Employers and even educational policy makers will now understand more clearly the standards and qualifications of graduates for career and accountability purposes (Maher, 2004).

\subsubsection{Flexibility}

As long as the same intended level of knowledge and skills is achieved, a great deal of flexibility is built into the model for choosing the means of instruction. In this regard, a variety of teaching and learning practices, approaches and even delivery modes can be deployed to accommodate various circumstances. Flexibility also occurs in recognizing prior student experience by comparing the different levels of learning outcomes within the framework (Maher, 2004).

\subsubsection{Comparison}

With the outcome approach, it is more feasible to develop comparable criteria for accreditation, benchmarking, and accountability purposes across programmes and even organizations. These summative and formative comparisons, according to Jackson (2000), can provide valuable information for students to be admitted, put or accredited in relation to their level of standards and results achieved, and will assist organizations, as they learn from each other through the cross-checking of outcomes, to review standards against each other and to benchmark for progress.

\subsubsection{Portability}

This is made possible by articulating the learning outcomes using clear criteria and credible expectations in various programmes. In this age of the student Maher (2004) argues that mobility and modularity of instructional provision will also allow increased mobility and exchange of students, not only locally, but internationally.

\subsection{The outcome-based education drawbacks}

Despite the many advantages it offers, the outcome-based approach is not without challenges. Ewell (2008) extends his review on the topic of advantages and problems by cautioning against four major disadvantages: definition, legitimacy, fractionation, and serendipity, which can arise when attempts are made at the level of implementation to operationalize outcomes. In addition, other drawbacks had been raised by the critics of this approach such as creativity stifling, the knowledge commodification, and the one size fitting all issue

\subsection{Definition}

Definitions of learning outcomes are subject to the context of their implementation and the decision of a particular team or group of interested individuals. Due to the sufficient specificity and consistency needed for a true and accurate decision on the skill or characteristic in question, the outcomes defined for a specific course or program could not be generalized across contexts (Ewell, 2008)

\subsection{Legitimacy}

Ewell ( 2008) points out that outcome statements, in their very nature, appear to break down holistic conceptions of learning, and reduce them to learning abilities or improvements in actions that are concrete, observable and measurable. As a consequence, outcome systems are still not generally accepted and understood in academia as a legitimate way of conceptualizing what learning is all about.

\subsection{Fractionation}




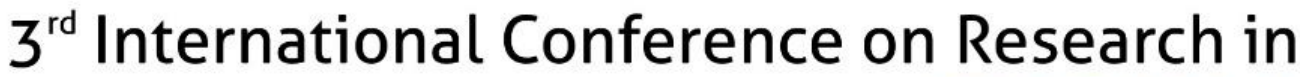 EDUCATION}

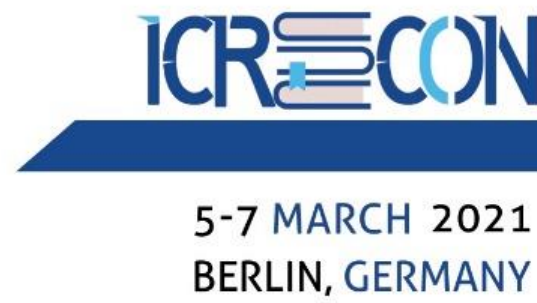

From the operational perspective, outcome measurement could become too centered on the learning of skills and expertise by the student that other more meaningful developmental results are overlooked over time. There may also be a lack of continuity in an educational program among smaller components as a result of fractionation that breaks down both learning and evaluation in small incremental units (Ewell, 2008). In evaluating learning, Ewell contends that the way evaluation operates in outcome systems can often be found to be too limited and even mechanical, lacking the essence of integrated ability that is expected to unite different discrete skill components into expert practice.

\subsection{Serendipity}

In a similar vein, outcomes-based approaches are criticised for their constrained serendipity which presumes that all of the valued and important ways that a learner can construct meaning in the context of a particular discipline or ability are known in advance (Ewell, 2008). This problem is conceived to be more pronounced in advanced levels of study and in certain disciplines such as fine arts where unexpected important learning may occur during the instructional process.

\section{5. Stifling students and teachers creativity}

The obligation to pre-specify learning outcomes at the start of a program or module may also have potentially negative effects on the learning experience of the student. For instance, the publication in course materials of pre-specified learning outcomes can unintentionally stifle innovation and originality in both teachers and students Maher (2004). Further more, they can produce what Ecclestone (1999:36) considers a 'subtle form of closure on thoughts about what is important in learning' with the marginalization of crucial or esoteric outcomes and discourses,

instrumental reasoning and surface learning. This view point is confirmed by Ecclestone (incidentally a keen supporter of outcomes-based curricula) who says : " If unchecked, there is a real danger that uncritical acceptance of increasingly prescriptive, standardised outcomes will create cynical, instrumental attitudes to learning in teachers and students alike and remove critical dimensions of student-centeredness from higher Education" (1999:29)

\subsection{The commodification of knowledge}

Hussey and Smith (2002) believe that there is a possibility that teachers will engage in a 'learning outcomes game' in which learning outcomes are treated as a chore rather than a valuable activity to enhance teaching and learning in order to comply with current quality assurance processes. Evidently, some critics anticipate a more insidious consequence of imposing on universities a 'learning outcomes regime' in that they can 'distort and weaken information by reducing it to commodified, decontextualized data. The growing focus on auditing and education accountability has contributed, according to Hussey and Smith (2002) opinion, to a decrease in confidence and the disempowerment and demoralization of academics

\subsubsection{One size fitting all}

In terms of the learning styles and skills needed at different levels, Hussey and Smith ( 2002) argue that various disciplines are very different. For example, from year one of their course, English literature students will be expected to assess and criticize, but this will not be a requirement for students of medicine or engineering. With respect to knowledge, learning outcomes need to allow for different degrees and this is very difficult to express precisely. Furthermore, learning outcomes, according to Hussey and Smith (2002) viewpoint, also require clarification and they seem to be obvious only to those who already know what they mean on the basis of their prior knowledge of the subject. Since students are unlikely to have sufficient levels of expertise, they do not have reference levels to correctly interpret the learning outcomes. 


\section{$3^{\text {rd }}$ International Conference on Research in EDUCATION}

\section{Conclusion}

While a greater use of outcomes-based learning has been seen in recent years to ensure educational efficiency and quality in HE, there are still some concerns about the way they are currently used. This approach, in fact, is based on sound principles of education and provides students with a strong foundation for learning the requisite skills. Nonetheless, it is subject to criticism and cautionary use, despite its usefulness. In this regard, some critics have claimed that if taken too far, learning outcomes can jeopardize more fundamental open-ended assumptions in student-centered learning. Moreover, they affirm that outcome mechanisms are overly specific, observable, quantifiable and so limited that they can be restricting rather than liberating, which can lead to reductionism, reification, fractionation, serendipity, and make them fail to foster creative thinking and achieve the form of learning and education that this approch offers. Accordingly, learning outcomes need to be described within a given context in a manner that is both responsive and flexible, and they should not be seen as an endeavor 'one and for all,' but rather an iterative process involving both learners and teachers in their development as active participants, and they should be also structured in a way that fosters innovation within the tasks of assessment which is at the heart of the experience of HE students.

Finally, it can be said that the transition to outcome-based education is a complex process that requires curriculum mapping to allow both teachers and students understand the expected progression and the complex relationship between learning outcomes, learning opportunities, curriculum content and properties and the assessment of students.

\section{References}

Adam, S. (2004) Using Learning Outcomes, Report for United Kingdom Bologna Seminar 12 July 2004, Heriot-Watt University (Edinburgh Conference Centre) Edinburgh. Scotland.

Adam, S. (2006). An introduction to learning outcomes. In Froment, J. Kohler, L. Purser, L. Wilson (Eds.), EUA Bologna Handbook (B2.3-1). Berlin, Raabe.

Anderson, L. W. and Krathwohl, D. R. (eds.) (2001) A Taxonomy for Learning, Teaching and Assessing: A Revision of Bloom's Taxonomy of Educational Objectives. New York: Longman.

Argyris, C. \& Schön, D. (1974), Theory in Practice: Increasing Professional Effectiveness, Jossey Bass, San Francisco, CA.

Bagnall, R. (1994). Performance indicators and outcomes as measures of educational quality: A cautionary critique. International Journal of Lifelong Education, 13(1), 19-32.

Bagnall, R. (2009). Values teaching and learning in vocational education and training: Trends and challenges. Internal paper, Hong Kong Institute of Education: Hong Kong.

Barr, R. B., \& Tagg, J. (1995). From teaching to learning-A new paradigm for undergraduate education. Change, 27, 18-25.

Biggs, J. (2001) The Reflective Institution: Assuring and Enhancing the Quality of Teaching and Learning. Higher Education, 41, 221-238.

Bloom, B. (1956) A Taxonomy of Cognitive Objectives. New York: McKay.

Coates, M. (2000) Compliance or creativity?: Using learning Outcomes to enhance learner autonomy. Academic Development - Challenges and Changes International Conference, South Africa: Rhodes University, December.

Doyle, W. (2006). State Accountability Policies and Boyer's Domains of Scholarship: 
Conflict or Collaboration? New Directions for Institutional Research, 129, 979-113.

Ecclestone, K. (1999) Empowering or Ensnaring?: Outcome-based Assessment in Higher Education. Higher Education Quarterly 53(1), 29-48.

Gosling, D. and Moon, J. (2001) How to Use Learning Outcomes and Assessment Criteria. London: SEEC.

Guthrie, J. \& Neumann, R. (2006). Performance Indicators in Universities: The Case of the Australian University System. (Submission for Public Management Review Final February 2006).

Harvey L. \& Green, D. (1993) "Defining quality", Assessment and Evaluation in Higher Education, Vol.18, pp.8-35

Hau, H. (1996), “Teaching Quality Improvement by Quality Improvement in Teaching”, Quality Engineering, Vol.9, No.1, pp.77-94

Hussey, T. and Smith, P. (2003) The Uses of Learning Outcomes. Teaching in Higher Education 8(3), 357-368.

Jackson, N. (2000) Programme specification and its role in promoting an outcomes model of learning. Active Learning in Higher Education 1(2), 132-151.

Kennedy, D., Hyland, A., \& Ryan, N. (2006). Writing and using learning outcomes: A practical guide. In Froment, J. Kohler, L. Purser, L. Wilson (Eds.), EUA Bologna Handbook (C3.4-1). Berlin: Raabe.

Maher, A. (2004). Learning Outcomes in Higher Education: Implications for Curriculum Design and Student Learning. Journal of Hospitality, Leisure, Sport and Tourism Education. Vol. 3, No. 2.

Maureen Tam (2014). Outcomes-based approach to quality assessment and curriculum improvement in higher education. Quality Assurance in Education. Vol. 22, No. 2.

Robertson, C. (2001) What's the Outcome? LINK 2, October. LTSN for Hospitality, Leisure, Sport and Tourism.

Scheerens, J., Luyten, H. and Van Ravens, J. (Eds.) (2011). Perspectives on Educational Quality: Illustrative Outcomes on Primary and Secondary Schooling in the Netherlands. Dordrecht, Heidelberg, London, New York: SpringerBriefs in Education.

Spady, W. G. (1994). Outcome-based education: Critical issues andanswers. Arlington, VA: American Association of School Administrators.

Strang, L.; Bélanger, J.; Manville, C.; Meads, C. (2016). Review of the Research Literature on Defining and Demonstrating Quality Teaching and Impact in Higher Education, York, United Kingdom: Higher Education Academy.

UDACE (1989) Understanding Learning Outcomes. London: National Institute of Adult Continuing Education.

UNESCO/CEPES (2003), "Higher Education in the Twenty-first Century : A Vision for the Future", Higher Education in Europe, Vol.28, No.1

Watson, P. (2002) The role and integration of learning outcomes into the educational process. Active Learning in Higher Education 3(3), 205-219. 